\title{
Change of Subjective Tinnitus by the Duration of Noise Exposure in Patients with Noise-Induced Hearing Loss
}

\author{
Jeonghyun Oh, Ju-Hwan Sim, and Sung Il Cho \\ Department of Otolaryngology-Head and Neck Surgery, Chosun University College of Medicine, Gwangju, Korea
}

\section{소음성 난청 환자에서 소음 노출 기간에 따른 주관적 이명의 변화}

오정현 · 심주환 · 조성일

조선대학교 의과대학 이비인후과학교실

Received December 8, 2017

Revised March 3, 2018

Accepted March 7, 2018

Address for correspondence

Sung Il Cho, MD, PhD

Department of Otolaryngology-

Head and Neck Surgery,

Chosun University

College of Medicine,

365 Pilmun-daero, Dong-gu,

Gwangju 61453, Korea

Tel $+82-62-220-3207$

Fax $+82-62-225-2702$

E-mail chosi@chosun.ac.kr
Background and Objectives Tinnitus, a common complaint of workers who are exposed to noise, can cause substantial negative effects on the quality of life of these workers. The aim of this study was to analyze the characteristics of tinnitus in patients with noise-induced hearing loss and the relationship between tinnitus and the duration of noise exposure.

Subjects and Method Thirty-three patients with subjective tinnitus and noise-induced hearing loss were included in this study. Tinnitus questionnaire, Tinnitus Handicap Inventory (THI) and audiological examinations were investigated according to the duration of noise exposure. Results There was a significant correlation between the tinnitus loudness and the duration of noise exposure. Patients who had longer periods of noise exposure had a louder tinnitus and higher THI score. However, there is no significant correlation between the characteristics of tinnitus and aging process.

Conclusion The duration of noise exposure influences the loudness and distress of tinnitus. An awareness of tinnitus should be considered as part of hearing conservation program. Korean J Otorhinolaryngol-Head Neck Surg 2018;61(12):669-73

Key Words Hearing loss $\cdot$ Noise $\cdot$ Tinnitus.

\section{서 론}

소음성 난청은 노화성 난청 다음으로 유병률이 높은 난청 유형으로 전 인구의 약 $1.7 \%$ 가 소음성 난청에 의한 장해를 가지고 있는 것으로 알려져 있으며 ${ }^{1)}$ 이명의 유병률은 $20.27 \%$ 로 보고되고 있다.2) 이명은 청력 손상과 연관되어 더 흔하게 발생할 수 있으며 난청 환자의 $75 \%$ 에서 호소한다고 알려져 있고 $^{3)}$ 산업 발달로 인한 소음 증가, 노령화, 약물복용 증가에 따라 이명도 증가하고 있다. ${ }^{4}$ 소음성 난청 환자에서 이명의 발생은 소음 노출 기간이 증가할수록 증가한다고 알려져 있

This is an Open Access article distributed under the terms of the Creative Commons Attribution Non-Commercial License (https://creativecommons.org/licenses/by-nc/4.0) which permits unrestricted non-commercial use, distribution, and reproduction in any medium, provided the original work is properly cited.
으낟) 아직까지 소음 노출 기간에 따른 이명의 변화에 관하 여서는 연구가 미비한 상황이다. 본 연구에서는 소음성 난청 환자에서 소음 노출 기간에 따라 이명의 크기와 불편감의 변 화를 알아보고자 하였다.

\section{대상 및 방법}

2015년 1월부터 2017년 6월까지 본원에 내원한 소음성 난 청 환자 62명 중 지속적인 주관적 이명을 호소하고 다른 원 인이 확인되지 않는 33명의 환자에게 설문지를 이용한 문진, 이경검사 등의 신체검사를 시행하였다. 고막함몰, 고막천공 및 만성중이염 소견을 보이는 경우, 두부외상이나 중이 수술 의 과거력이 있는 경우, 전음성 난청이나 전농인 경우는 연구 
에서 제외하였다. 본 연구는 병원 임상시험 심사위원회(Institutional Review Board)의 승인(IRB No. 2017-09-016)을 얻 었으며 소음성 난청은 고용노동부의 소음성 난청 진단기준 에 따라 소음작업장에 1년 이상 근무하였으며, 순음 청력 검 사상 $500,1000,2000 \mathrm{~Hz}$ 에서의 기도 청력 평균이 $30 \mathrm{~dB}$ 이상 의 청력손실이 있거나 $4000 \mathrm{~Hz}$ 에서 $40 \mathrm{~dB}$ 이상의 청력손실 이 있는 경우로 정의하였다. ${ }^{6}$ 과거력상 환자들은 동일한 광 업소에서 하루 8시간씩 근무를 하였으며 해당 작업장의 소

Table 1. Baseline characteristics of tinnitus patients with noise-induced hearing loss

\begin{tabular}{|c|c|c|c|}
\hline & $\begin{array}{c}\text { Tinnitus }(+) \\
(n=33)\end{array}$ & $\begin{array}{l}\text { Tinnitus }(-) \\
\quad(n=29)\end{array}$ & $\begin{array}{c}\text { Total } \\
(n=62)\end{array}$ \\
\hline \multicolumn{4}{|l|}{ Gender } \\
\hline Male & 32 & 29 & 61 \\
\hline Female & 1 & 0 & 1 \\
\hline \multicolumn{4}{|l|}{ Age (year) } \\
\hline $50-55$ & 3 & 0 & 3 \\
\hline $56-60$ & 2 & 0 & 2 \\
\hline $61-65$ & 4 & 2 & 6 \\
\hline $66-70$ & 5 & 5 & 10 \\
\hline $71-75$ & 9 & 10 & 19 \\
\hline $76-80$ & 8 & 6 & 14 \\
\hline $80<$ & 2 & 6 & 8 \\
\hline \multicolumn{4}{|c|}{ Noise exposure (year) } \\
\hline$\leq 10$ & 7 & 3 & 10 \\
\hline $11-20$ & 9 & 13 & 22 \\
\hline $20<$ & 17 & 13 & 30 \\
\hline \multicolumn{4}{|l|}{ Past history* } \\
\hline Yes & 15 & 10 & 25 \\
\hline No & 18 & 19 & 37 \\
\hline \multicolumn{4}{|l|}{ Tinnitus location } \\
\hline Unilateral right & 9 & & \\
\hline Unilateral left & 9 & & \\
\hline Bilateral & 15 & & \\
\hline \multicolumn{4}{|c|}{$\begin{array}{l}\text { Subjective judgement } \\
\text { of tinnitus }\end{array}$} \\
\hline Pure tone & 11 & & \\
\hline Narrow band & 11 & & \\
\hline Warble tone & 3 & & \\
\hline Undetermined & 8 & & \\
\hline
\end{tabular}

*heart disease, hypertension, stroke, asthma, diabetes, kidney disease, pneumoconiosis
음은 90 119 dB로 측정되었다. 방음실에서 순음 청력 검사 기를 사용하여 pitch, intensity match 방법으로 250 8000 $\mathrm{Hz}$ 의 순음 또는 대역잡음을 들려주고 이명과 가장 비슷한 주파수와 크기를 선택하여 이명의 주파수와 크기를 측정하 였다. 이명의 불편감 측정을 위해 이명 불편감 척도(Tinnitus Handicap Inventory, THI)를 이용하여 이명에 의한 주관적 인 불편감을 점수화하여 측정하였다. 통계학적 분석은 SPSS version 15.0(SPSS Inc., Chicago, IL, USA)을 사용하였으며 이명의 크기, 불편감의 결과는 Kruskal-wallis test, Mannwhitney test, 회귀분석을 이용하여 분석하였고 이명 주파수 별 이명의 크기, 불편감의 결과는 Pearson 상관분석을 시행 하였으며 $p$ 값이 0.05 미만일 때 통계학적으로 유의하다고 판 단하였다.

\section{결 과}

\section{사회인구학적 특성}

소음성 난청 환자 62 명 중 10 년 이하의 소음 노출을 보인 군 10명에서 7명(70\%), 11 20년 사이의 군 22명에서 9명(40.92\%), 20년 초과 군 30명에서 17명(56.6\%)이 지속적인 주관적 이명 을 호소하였다. 환자의 연령은 53 83세였으며 평균 70세였 다. 65세 미만이 10명(27.3\%), 65세 이상이 23명(72.7\%)이었다. 소음 노출 기간별로 볼 때 10 년 이하의 소음 노출을 보인 군 은 7명(21.2\%), 11 20년 사이의 군은 9명(27.2\%), 20년 초과 군은 17 명 (51.6\%)을 보였다. 소음 노출 기간별 소음 노출과 이명의 발생 시점까지의 기간은 10 년 이하의 소음 노출을 보

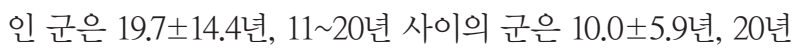
초과 군은 $15.4 \pm 7.5$ 년이었다. 심장질환이나 고혈압, 뇌졸중, 천식, 당뇨, 신장질환이나 진폐증과 같은 기저질환을 가진 환 자는 15 명 $(45.4 \%)$ 이었다. 이명을 호소하는 귀가 우측인 환자 는 9명(27.2\%), 좌측인 경우는 9명(27.2\%), 양측인 경우는 15 명(45.6\%)이었다. 주관적 이명의 평가에서는 순음과 협대역 잡음이 각각 11 명(33.3\%)으로 가장 많은 비율을 차지하였으며 진동음이 3 명(9.2\%), 구분되지 않는 소리를 호소하는 환자가 8명(4.3\%)이었다(Table 1). 순음 청력 검사상 청각 역치는 소 음 노출 기간이 증가할수록 증가하였으며 65세 이상군에서 증가하였다(Table 2).

Table 2. Hearing thresholds according to the duration of noise exposure and age

\begin{tabular}{|c|c|c|c|c|c|}
\hline & \multicolumn{3}{|c|}{ Noise exposure (year) } & \multicolumn{2}{|c|}{ Age (year) } \\
\hline & $\leq 10$ & $10-20$ & $20<$ & $<65$ & $65 \leq$ \\
\hline \multicolumn{6}{|c|}{ Hearing thresholds $(\mathrm{dB})$} \\
\hline $\mathrm{R} \dagger$ & $47.1 \pm 4.4$ & $51.4 \pm 7.9$ & $52.6 \pm 10.6$ & $44.6 \pm 8.4$ & $54.0 \pm 7.7$ \\
\hline L† & $52.1 \pm 14.9$ & $54.1 \pm 14.6$ & $56.6 \pm 14.1$ & $48.8 \pm 17.5$ & $58.2 \pm 11.3$ \\
\hline
\end{tabular}




\section{소음 노출 기간 및 연령에 따른 이명의 특성}

환자들이 호소하는 이명의 주파수는 65세 미만에서 소음 노출 기간이 10 년 이하인 군은 $2.2 \pm 1.7 \mathrm{kHz}, 11$ 20년 군은 $1.7 \pm 1.4 \mathrm{kHz}, 20$ 년 초과 군은 $2.7 \pm 1.2 \mathrm{kHz}$ 이고 연령이 65세 이상인 이명 환자의 주파수는 각각 $1.3 \pm 0.8 \mathrm{kHz}, 1.8 \pm 1.4$ $\mathrm{kHz}, 1.7 \pm 1.4 \mathrm{kHz}$ 이었으며 소음 노출 기간과 연령에 따른 이명 주파수는 통계학적으로 유의한 차이가 없었다(Table 3). 이명의 크기는 소음 노출 10 년 이하인 군에서 $50.0 \pm 7.7 \mathrm{~dB}$, $11 \sim 20$ 년 사이의 군에서 $65.5 \pm 12.3 \mathrm{~dB}, 20$ 년 초과 군에서는 $71.5 \pm 10.3 \mathrm{~dB}$ 을 보였다. 각각의 군에서 소음 노출 기간이 증가 함에 따라 유의하게 이명의 크기가 증가하였다 $(p<0.05)$ (Fig. 1). 이명 불편감(THI)은 소음 노출 기간이 10 년 이하인 군은 $27.7 \pm 8.9$ 점, 11 20년 사이의 군은 $34.8 \pm 15.2$ 점, 20년 초과 군 은 47.2 \pm 12.9 점을 보였다. 소음 노출 기간이 증가함에 따라 이명의 불편감이 증가하였으며 10년 이하인 군과 20년 초과 군은 유의한 증가를 보였다 $(p<0.05)(\mathrm{Fig} .2)$. 소음성 난청 환 자에서 이명의 특징이 연령이 증가함에 따라 변하는지 알아 보고자 노화성 난청의 기준인 65 세를 기준으로 분류하여 분 석하였다. 이명의 크기는 65 세 미만 군에서는 $63.0 \pm 14.1 \mathrm{~dB}$, 65 세 이상인 군에서 $66.3 \pm 12.9 \mathrm{~dB}$ 로 두 군 간의 유의한 차이
는 없었다(Fig. 3). 이명의 불편감(THI)은 65세 미만 군에서는 $37.2 \pm 12.8$ 점, 65 세 이상인 군에서 $40.8 \pm 12.8$ 점으로 두 군 간 의 유의한 차이는 없었다(Fig. 4). 환자가 호소하는 이명의 주 파수별로 소음 노출 기간, 이명의 크기, 이명의 불편감을 분석 하였으나 유의한 차이는 관찰되지 않았다(Table 4).

\section{고 찰}

소음성 난청은 이명의 원인으로 생각되는 질환 중 원인 불 명의 감각신경성 난청에 이어 두 번째로 많은 질환이다. ${ }^{7}$ 본 연구에서는 단일 소음 사업장에서 근무한 소음성 난청 환자 를 대상으로 소음 노출 기간에 따른 이명의 크기 변화와 THI 설문을 이용한 불편감의 변화를 알아본 결과 소음 노출 기 간이 증가함에 따라 이명의 크기와 불편감이 유의하게 증가 하였다. 이는 소음 노출 기간이 증가함에 따라 난청의 정도가 증가한 것처럼 이명의 증상이 악화될 수 있음을 보여 준다. 소음성 난청이 증가하면 청각 박탈에 의해 피질지도(cortical tonotopic map)가 변화될 수 있으며 원래보다 많은 수의 뉴런 세포들이 제한된 범위의 말초 수용기에 대응하게 되고 상대 적으로 이전보다 많은 뉴런 세포들이 자극에 반응하는 동시

Table 3. Tinnitus characteristics and Tinnitus Handicap Inventory score according to the duration of noise exposure

\begin{tabular}{|c|c|c|c|c|c|c|c|c|}
\hline \multirow{2}{*}{$\begin{array}{c}\text { Noise exposure } \\
\text { (year) }\end{array}$} & \multicolumn{2}{|c|}{ Tinnitus ( $\mathrm{n}$ ) } & \multicolumn{2}{|c|}{ Pitch $(\mathrm{kHz})$} & \multicolumn{2}{|c|}{ Loudness (dB) } & \multicolumn{2}{|c|}{ Tinnitus Handicap Inventory } \\
\hline & $<65$ & $65 \leq$ & $<65$ & $65 \leq$ & $<65$ & $65 \leq$ & $<65$ & $65 \leq$ \\
\hline$\leq 10$ & 3 & 4 & $2.2 \pm 1.7$ & $1.3 \pm 0.8$ & $46.5 \pm 2.8$ & $52.5 \pm 8.6$ & $30.0 \pm 12.8$ & $25.5 \pm 5.7$ \\
\hline $11-20$ & 3 & 6 & $1.7 \pm 1.4$ & $1.8 \pm 1.4$ & $65.0 \pm 10.5$ & $65.8 \pm 12.4$ & $36.0 \pm 10.1$ & $34.5 \pm 18.0$ \\
\hline $20<$ & 4 & 13 & $2.7 \pm 1.2$ & $1.7 \pm 1.4$ & $73.5 \pm 4.7$ & $70.7 \pm 11.6$ & $43.0 \pm 15.0$ & $48.6 \pm 17.0$ \\
\hline
\end{tabular}

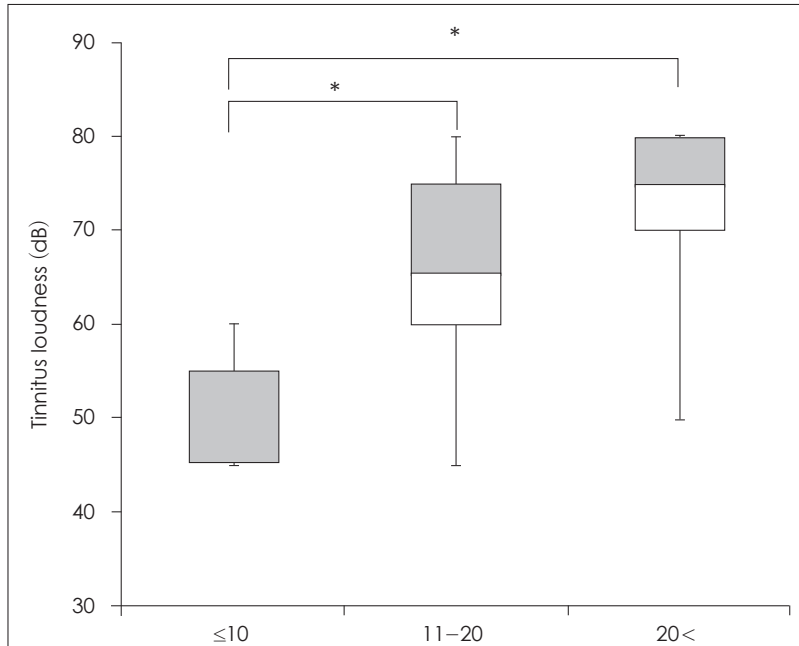

A

Duration of noise exposure (year)

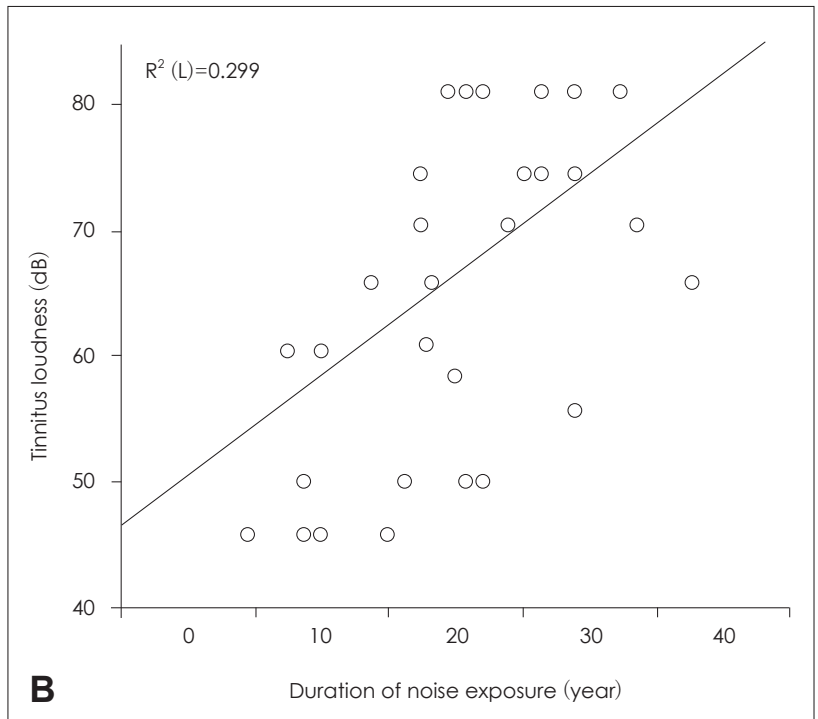

Fig. 1. Tinnitus loudness by the duration of noise exposure. Gray box displays the distribution from median to upper quartile and white box does from lower quartile to median $\left(A,{ }^{*} p<0.05\right)$. Regression analysis between tinnitus loudness and the duration of noise exposure (B). 
신경 활성도(synchronous neural activity)가 증가되어 이명 의 크기가 증가할 수 있다. ${ }^{899}$ 소음 노출 기간이 길어짐에 따라 난청의 크기가 증가하면서 더욱 광범위한 토노토피 재조직 화(tonotopy reorganization)가 이루어져 소음 노출 기간이
증가할수록 이명의 크기가 증가하였던 것으로 생각된다.

소음성 난청과 동반된 이명이 노화에 의하여 변하는지 알 아보고자 65세를 기준으로 두 군으로 나누어 같은 소음 노출 기간을 가진 환자들의 이명 크기와 불편감을 비교한 결과 65
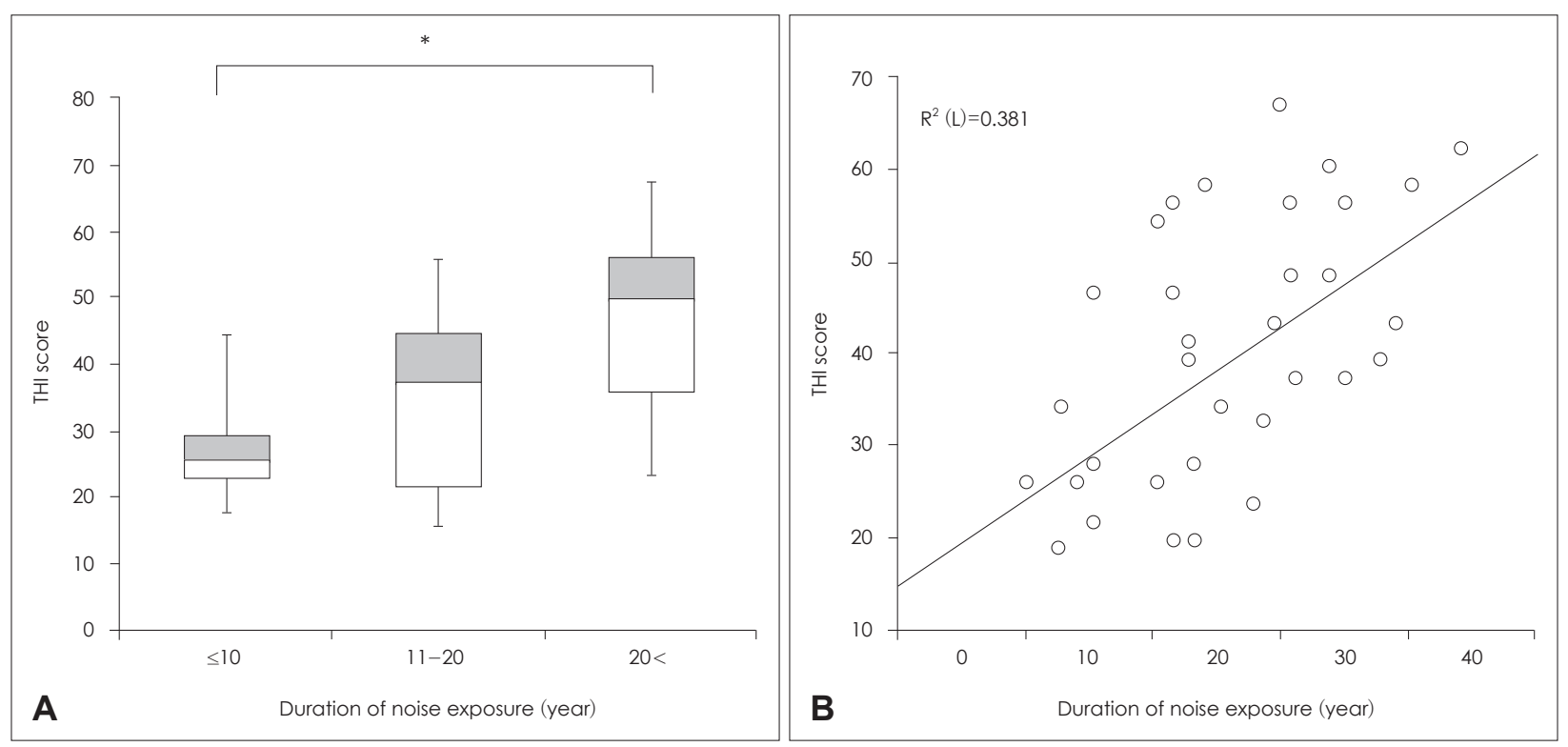

Fig. 2. THI score by the duration of noise exposure. Gray box displays the distribution from median to upper quartile and white box does from lower quartile to median $\left(A,{ }^{*} p<0.05\right)$. Regression analysis between THI score and the duration of noise exposure (B). THI: Tinnitus Handicap Inventory.

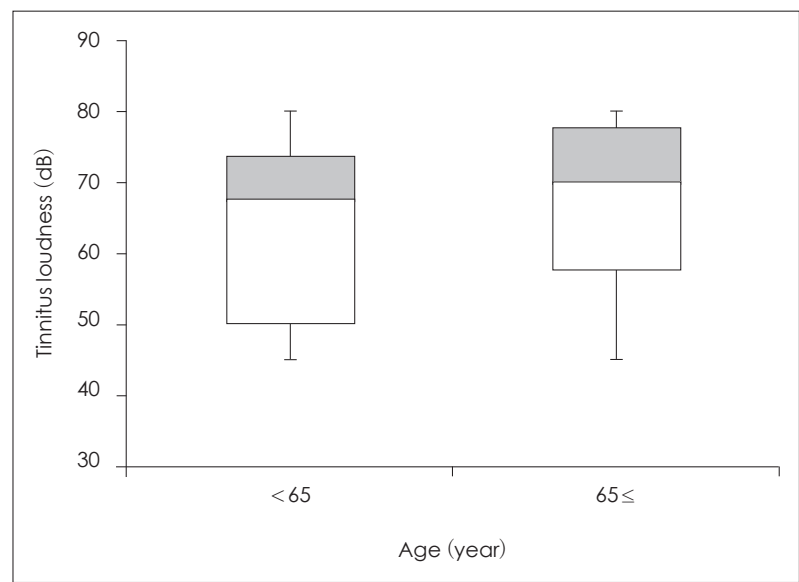

Fig. 3. Tinnitus loudness by age group. Gray box displays the distribution from median to upper quartile and white box does from lower quartile to median.

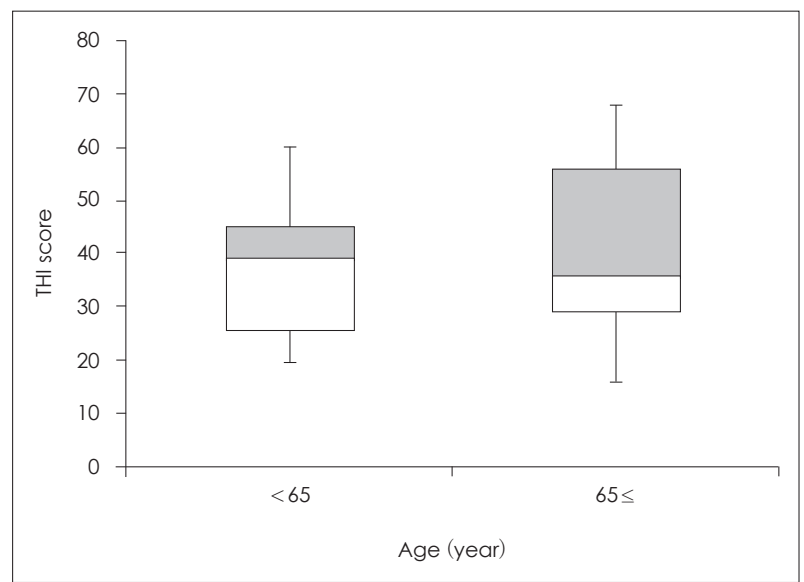

Fig. 4. THI score by age group. Gray box displays the distribution from median to upper quartile and white box does from lower quartile to median. THI: Tinnitus Handicap Inventory.

Table 4. The duration of noise exposure, tinnitus loudness, Tinnitus Handicap Inventory score, and Visual Analogue Scale according to the pitch of tinnitus

\begin{tabular}{lcccc}
\hline \multicolumn{1}{c}{ Pitch $(\mathrm{kHz})$} & Noise exposure (year) & Loudness $(\mathrm{dB})$ & Tinnitus Handicap Inventory & Visual Analogue Scale \\
\hline $0.25(\mathrm{n}=4)$ & $27.5 \pm 5.3$ & $72.5 \pm 11.9$ & $38.0 \pm 12.9$ & $5.5 \pm 2.3$ \\
$0.5(\mathrm{n}=5)$ & $12.4 \pm 6.3$ & $55.0 \pm 14.1$ & $47.0 \pm 15.9$ & $7.0 \pm 0.7$ \\
$1(n=5)$ & $28.4 \pm 8.6$ & $71.0 \pm 8.9$ & $53.4 \pm 20.3$ & $5.6 \pm 3.2$ \\
$2(n=10)$ & $19.5 \pm 8.1$ & $67.0 \pm 11.5$ & $39.3 \pm 15.1$ & $4.9 \pm 2.8$ \\
$3(n=4)$ & $22.2 \pm 7.1$ & $62.5 \pm 17.6$ & $31.0 \pm 9.3$ & $5.5 \pm 1.9$ \\
$4(n=5)$ & $20.6 \pm 6.6$ & $63.0 \pm 14.8$ & $35.4 \pm 14.3$ & $5.2 \pm 2.1$ \\
\hline
\end{tabular}


세 미만 군과 이상 군의 차이는 없었다. 이명의 크기나 불편 감은 난청, 피로와 같은 체성 증상, 스트레스와 밀접한 관련 이 있으며 ${ }^{10,11}$ 난청 환자가 스트레스 상황에 노출 시에는 이 명의 크기가 증가할 수 있고 이명에 변연계(limbic system)와 자율신경계 같은 스트레스 네트워크가 관여한다고 알려져 있다. ${ }^{12,13)}$ 소음에 노출된 과거력을 가진 65 세 이상의 인구에서 는 소음성 난청 외에 노화성 난청으로 난청의 크기가 증가할 수는 있으나 상대적으로 과도한 업무 및 스트레스 상황에 덜 노출되는 경향이 있어 소음성 난청 환자가 연령이 증가하여 도 이명의 크기와 불편감이 변하지 않는 것으로 생각된다.

그동안 난청의 크기와 이명의 주파수를 비교한 연구에서 두 가지 인자의 상관관계가 없는 것으로 보고되었다. ${ }^{14,15)}$ 특 히, 청각 역치가 가장 높은 주파수와 이명의 주파수를 분석 한 결과에서도 상관관계가 관찰되지 않았다. ${ }^{16)}$ 또한, 노화성 난청 환자에서 난청의 크기와 이명의 주파수를 분석한 결과 에서도 상관관계가 관찰되지 않았다. ${ }^{15)}$ 본 연구에서는 소음 노출 기간과 연령에 따라 이명의 주파수 변화를 분석하였으 나 유의한 차이는 관찰되지 않았다. 이와 같은 결과는 소음 성 난청이 초기에 $4 \mathrm{kHz}$ 의 난청으로 시작되고 점점 다른 주 파수로 확대되어 청각 역치가 증가하지만, 이명의 주파수는 난청의 주파수 영역이나 크기에 상관없이 나타날 수 있으며 연령이 증가함에 따라 노화성 난청이 동반되더라도 이명의 주파수 변화에는 영향을 미치지 않는 것으로 보인다.

결론적으로 소음 노출 기간이 증가함에 따라 난청의 크기 증가와 이에 따른 광범위한 토노토피 재조직화로 이명의 크 기와 불편감이 증가한 것으로 생각된다. 소음 환경에서 작업 하는 작업자의 경우 소음 노출 기간을 줄이는 것이 이명의 관 리에 중요한 문제이며 난청 이외에 이명이 소음 작업장 관리 의 중요한 목적으로 포함되어야 할 것이다. 하지만, 본 연구의 연구 대상자 수가 적어 추후 더 많은 대상자를 포함한 추가 연구가 필요할 것으로 생각된다.

\section{Acknowledgments}

This research was supported by Basic Science Research Program through the National Research Foundation of Korea (NRF) funded by the Ministry of Education (2015R1D1A1A01058815).

\section{REFERENCES}

1) Boger ME, Sampaio ALL, Oliveira CACP. Analysis of hearing and tinnitus in workers exposed to occupational noise. Int Tinnitus $\mathrm{J}$ 2017;20(2):88-92.

2) Cho YS, Choi SH, Park KH, Park HJ, Kim JW, Moon IJ, et al. Prevalence of otolaryngologic diseases in South Korea: data from the Korea national health and nutrition examination survey 2008. Clin Exp Otorhinolaryngol 2010;3(4):183-93.

3) Phoon WH, Lee HS, Chia SE. Tinnitus in noise exposed workers. Occu Med (Lond) 1993;43(1):35-8.

4) Kim KS, Chung HK. Characteristics and affecting factors of tinnitus in noise exposed workers. Korean J Occup Environ Med 2002;14 (4):436-47.

5) Bhatt JM, Lin HW, Bhattacharyya N. Prevalence, severity, exposures, and treatment patterns of tinnitus in the United States. JAMA Otolaryngol Head Neck Surg 2016;142(10):959-65.

6) Jeon J, Chon KM, Goh EK, Lee IW, Cho KS, Ahn JH. Frequencies of tinnitus and noise of the factory in noise-induced hearing loss. Korean J Otorhinolaryngol-Head Neck Surg 2005;48(2):142-5.

7) Goh EK. Residual inhibition of tinnitus after masking with various sounds. Korean J Otorhinolaryngol-Head Neck Surg 1990;33(4):65770.

8) Noreña AJ, Eggermont JJ. Enriched acoustic environment after noise trauma abolishes neural signs of tinnitus. Neuroreport 2006;17(6): $559-63$.

9) Eggermont JJ, Roberts LE. The neuroscience of tinnitus: understanding abnormal and normal auditory perception. Front Syst Neurosci 2012; 6:53.

10) Brüggemann P, Szczepek AJ, Rose M, McKenna L, Olze H, Mazurek B. Impact of multiple factors on the degree of tinnitus distress. Front Hum Neurosci 2016;10:341.

11) Baigi A, Oden A, Almlid-Larsen V, Barrenäs ML, Holgers KM. Tinnitus in the general population with a focus on noise and stress: a public health study. Ear Hear 2011;32(6):787-9.

12) Mazurek B, Haupt H, Olze H, Szczepek AJ. Stress and tinnitus-from bedside to bench and back. Front Syst Neurosci 2012;6:47.

13) Vanneste $S$, De Ridder D. The auditory and non-auditory brain areas involved in tinnitus. an emergent property of multiple parallel overlapping subnetworks. Front Syst Neurosci 2012;6:31.

14) Flores LS, Teixeira AR, Rosito LP, Seimetz BM, Dall'Igna C. Pitch and loudness from tinnitus in individuals with noise-induced hearing loss. Int Arch Otorhinolaryngol 2016;20(3):248-53.

15) Seimetz BM, Teixeira AR, Rosito LP, Flores LS, Pappen CH, Dall'igna C. Pitch and loudness tinnitus in individuals with presbycusis. Int Arch Otorhinolaryngol 2016;20(4):321-6.

16) Sereda M, Edmondson-Jones M, Hall DA. Relationship between tinnitus pitch and edge of hearing loss in individuals with a narrow tinnitus bandwidth. Int J Audiol 2015;54(4):249-56. 